\title{
Responses of neurons in the lamb nucleus tractus solitarius to stimulation of the caudal oral cavity and epiglottis with different stimulus modalities
}

\author{
Robert D. Sweazey ${ }^{1}$ and Robert M. Bradley ${ }^{1,2}$ \\ 'Department of Biologic and Materials Sciences, School of Dentistry, The University of Michigan, Ann Arbor, MI 48109 (U.S.A.) and \\ ${ }^{2}$ Department of Physiology, School of Medicine, The University of Michigan, Ann Arbor, MI 48109 (U.S.A.)
}

(Accepted 26 July 1988)

Key words: Chemosensitive; Epiglottis; Multimodal; Mechanosensitive; Nucleus tractus solitarius; Oral cavity; Palate; Receptive field; Sheep; Thermosensitive; Tongue

\begin{abstract}
Receptors located in the posterior oral cavity and on the epiglottis play an important role in the initiation of upper airway reflexes such as swallowing, gagging, coughing and apnea. Peripheral nerves which innervate these receptor areas terminate in the nucleus tractus solitarius (NTS). We have recorded the responses of 61 neurons in the lamb NTS to stimulation of the caudal tongue, palate and epiglottis with mechanical, chemical and thermal stimuli and mapped receptive field location. Although there was some overlap in the areas of the NTS from which neurons with oral cavity and epiglottal receptive fields could be recorded, a significant difference was observed in the mean recording sites of the two groups of neurcns. Neurons with oral cavity receptive fields were located more rostral, lateral and ventral in the NTS than neurons with receptive fields on the epiglottis. Little convergence of sensory input onto single cells in the NTS was observed between the oral cavity and the epiglottis. Only one NTS neuron had a receptive field in both of these receptor areas. In contrast, a large number of neurons with oral cavity receptive fields received input from two receptor areas. These neurons had a receptive field on the tongue which was located directly beneath the receptive field on the palate. Mechanical stimuli were the most effective for neurons with either oral cavity or epiglottal receptive fields and thermal stimuli were the least effective. Neurons which responded to mechanical stimuli responded better to a moving stimulus than to a punctate one, and large increases in the strength of a punctate stimulus were required to elicit significant increases in response frequency. Most NTS neurons responded to more than one of the stimulus modalities. However, a significant difference in the mean number of stimulus modalities which elicited responses was observed between neurons with oral cavity and epiglottal receptive fields. The number of multimodal neurons with epiglottal receptive fields was higher than those with oral cavity receptive fields. The multimodal nature of neurons which responded to epiglottal or oral cavity stimulation combined with their locsicion in reflexogenic areas of the NTS suggests that these neurons could be important in the integration of afferent input from the oral cavity and upper airway. If these NTS neurons are involved in the control of oral and upper airway reflexes it would be important for them to respond to as many of the stimulus cues as possible and the majority of these neurons do just that.
\end{abstract}

\section{INTRODUCTION}

Receptors located in the posterior oral cavity and larynx play an important role in the initiation of upper airway reflexes such as swallowing, coughing, apnea and gagging $18,30,33,37,49,56$. These reflexes can be evoked by a variety of stimuli ${ }^{4.30 .55}$ and the type of refiex response produced by peripheral stimulation depends on the interaction of the stimulus and the specific receptor area stimulated ${ }^{38,55,56}$. For example, the most effective receptor areas for the initiation of swallowing and apnea are the regions on and around the laryngeal surface of the epiglottis. Applications of a number of different stimulus modalities will elicit these reflexes, but chemical stimuli are the most effective $e^{55.56 .60}$. In contrast to the actions of chemical stimuli on the epiglottis, stimulation of the caudal tongue and palate with chemicals is less effective in eliciting swallowing, but mechanical stimulation of these regions will often lead to swallowing, gagging

Correspondence: R.D. Sweazey, Department of Biologic and Materials Sciences, School of Dentistry, The University of Michigan, Ann Arbor, MI 48109, U.S.A. 
or reflexive tongue movements ${ }^{19,66}$.

Sensory information from the caudal oral cavity, epiglottis and larynx is conveyed centrally by nerves which terminate in the brainstem. One of the projection areas of these sensory fibers is the nucleus tractus solitarius (NTS) ${ }^{2.11,41,42,61}$. Most of the caudal oral cavity afferent fibers which terminate in the NTS do so in the rostral region where gustatory information is processed ${ }^{2,15,22}$.

However, some afferent fibers terminate more caudally in regions of the NTS which receive afferent input from the epiglottis and larynx via the superior laryngeal nerve (SLN) ${ }^{22.61}$. These more caudal regions of the NTS are important in the reflex initiation of swallowing and other upper airway reflexes ${ }^{24,37,54}$. Studies conducted using electrical stimulation of the peripheral nerves innervating the caudal oral cavity and epiglottis suggest that neurons in this reflexogenic region of the NTS receive input from these two receptor areas ${ }^{52.53}$. However, evidence using more natural stimuli is currently limited, with most investigations concentrating on the responses of neurons which receive information from upper airway receptor areas.

Because reflexes of the upper airway can be produced by stimulation with more than one stimulus modality, neurons in reflexogenic areas of NTS may play an integrative role in the processing of sensory information from the caudal oral cavity or epiglottis. Despite this fact, investigations of NTS neural responses to stimulation of the caudal oral cavity or epiglottis have usually concentrated on only one stimulus modality ${ }^{62.64}$, or have concentrated on the rostral

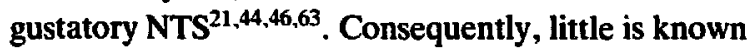
about the response characteristics of NTS neurons responsive to epiglottal or caudal oral cavity srimulation that are located more caudally in the NTS. In lambs the structure, number and distribution of taste buds in the oral cavity and epiglottis have been described $^{7-9.40}$, there is information on reflex responses to stimulation of structures in the upper airway ${ }^{28,29,31}$, and the responses of NTS neurons and glossopharyngeal and SIN fibers to chemical stimuli have been reported $^{12,39,62}$. Furthermore, the large size of the lamb caudal oral cavity and epiglottis permits mechanical stimulation of restricted areas. Consequently, lambs were used in our investigation of the responses of NTS neurons to stimulation of the caudal oral cavity and epiglottis. The presint study was designed to examine the response characteristics of neurons in regions of the lamb NTS where afferent fibers from the caudal oral cavity and epiglottis both terminate. The purpose of the study was to determine whether neurons in this region receive converging inputs from different receptor areas and to investigate the neural responses to different stimulus modalities.

\section{MATERIALS AND METHODS}

\section{Surgical preparation}

Thirty-six Suffolk lambs (aged 30-80 days) were anesthetized with an i.v. injection of sodium pentobarbital $(20 \mathrm{mg} / \mathrm{kg})$ and placed on a heating pad adjusted to maintain body temperature at $39^{\circ} \mathrm{C}$, monitored by rectal probe. The jugular vein was cannulated for administration of supplemental anesthetics and a tracheostomy performed close to the sternal notch.

The epiglottis was exposed by making a midline incision from the first tracheal cartilage to the base of the epiglottis and retracting the walls of the larynx to expose the interior. The epiglottis was reflected caudally into the open larynx using a laryngoscope so that its laryngeal surface, on which the taste buds reside, was visible through the incision, and the epiglottis was held in this position with a suture ${ }^{58}$. The epiglottis was covered with saline-soaked cotton until stimulation commenced and the esophagus was ligated to prevent solutions from being ingested. Exposure of the oral cavity was accomplished by making a bilateral incision through the buccal walls to the ramus of the jaw. A string placed around the lower incisors retracted the lower jaw downward to expose the caudal areas of the oral cavity. The oral cavity was covered with water-soaked cotton until stimulation commenced.

The animal was placed in a prone position and the head fixed with the nose downward in a stereotaxic frame. The skull and dura covering the medulla were removed, and the caudal cerebellum was aspirated to reveal the floor of the fourth ventricle. The exposed brain was then covered with paraffin oil at $39^{\circ} \mathrm{C}$. The stereotaxic frame was rotated $45^{\circ}$ from horizontal to permit both stimulation of the epiglottis from below and stimulation of the caudal tongue and palate while recording from single brainstem neurons. 


\section{Neurophysiology}

Using the obex as a zero reference point, epoxycoated tungsten microelectrodes (2-3 MS impedance) were positioned over the solitary complex and advanced into the brain with a micromanipulator. The search for responsive neurons concentrated on the intermediate one-third of the NTS from 3.0 to 5.0 $\mathrm{mm}$ rostral to obex. This region was chosen because it receives afferent terminations from both the lingual-tonsillar branch of the glossopharyngeal nerve which innervates the caudal oral cavity, and the SLN which innervates the epiglottis ${ }^{61}$. Furthermore, investigations have shown that this area of the lamb NTS is involved in processing upper airway chemosensory information and is important for some upper airway reflexes ${ }^{26,62}$. Electrode tracks were made between 2.5-6.0 mm rostral to obex. The initial electrode track was located between $3.5-4.5 \mathrm{~mm}$ rostral to obex, and at the medial or lateral border of the NTS. From this initial location, subsequent tracks were made by systematically moving in medial-lateral or caudal-rostral steps, to zigzag through the nucleus. Each successive electrode track was separated from the previous one by $300 \mu \mathrm{m}$.

The activity of single neurons was amplified, displayed on an oscilloscope and monitored with an audio amplifier. Neural data was stored on one channel of a magnetic tape recorder with voice cues of experimental procedure on a second channel. Neural activity was classified as coming from a single neuron on the basis of an action potential of constant amplitude and waveform. Single NTS neurons were located either by stroking the receptor areas with a soft brush, or by applications of warm and cool rinse solutions, or a mixture of the test chemical solutions. These stimuli have previously been shown to be effective for lamb and sheep superior laryngeal and glossopharyngeal nerve fibers ${ }^{12.39}$ and NTS neurons $^{10.62}$. After a neuron was isolated, its receptive field was determined using a glass probe, or a chemical soaked brush if the neuron was not responsive to mechanical stimuli. The receptive fields were mapped onto representative drawings of the oral cavity or epiglottis, and neural responses to mechanical, thermal and chemical stimuli recorded.

\section{Stimuli}

Chemical. Stimuli applied to the tongue and palate were $0.5 \mathrm{M} \mathrm{KCl}, 0.5 \mathrm{M} \mathrm{NH}_{4} \mathrm{Cl}, 0.01 \mathrm{~N} \mathrm{HCl}$ and 0.154 $\mathrm{M} \mathrm{NaCl}$ dissolved in distilled water. Distilled water also served as the rinse. Solutions applied to the epiglottis were $0.5 \mathrm{M} \mathrm{KCl}, 0.5 \mathrm{M} \mathrm{NH}_{4} \mathrm{Cl}, 0.01 \mathrm{~N} \mathrm{HC}$ and distilled water. Although water does not elicit responses from the posterior tongue, it does elicit a neural response in the SLN and NTS when applied to the epiglottis. Therefore, the chemicals which were applied to the epiglottis were dissolved in $0.154 \mathrm{M}$ $\mathrm{NaCl}$ which elicits minimal activity in the SLN fibers and NTS neurons during epiglottal stimulation, ${ }^{5,12}$, 58,62 . This concentration of $\mathrm{NaCl}$ was also used as a rinse solution to remove chemical stimuli from the epiglottis.

Syringes $(10 \mathrm{ml})$ fitted with 19-gauge needles were used to deliver $10 \mathrm{ml}$ of a stimulus solution to the receptor areas. Each chemi:al solution remained on the mucosa for $20 \mathrm{~s}$ and was then removed by application of $40 \mathrm{ml}$ of the appropriate rinse solution from a $50 \mathrm{ml}$ syringe. Stimuli were delivered at a flow rate of $10 \mathrm{ml} / 12 \mathrm{~s} \pm 1 \mathrm{~s}$ and all chemical and rinse solutions were delivered at oral cavity-epiglottis temperature $\left(33^{\circ} \mathrm{C}\right)$. Stimuli for the oral cavity were applied in the following sequence: $\mathrm{NH}_{4} \mathrm{Cl}, \mathrm{KCl}, \mathrm{HCl}, \mathrm{NaCl}$, $\mathrm{NH}_{4} \mathrm{Cl}$. Previous recordings from sheep glossopharyngeal nerve fibers demonstrated that $\mathrm{NH}_{4} \mathrm{Cl}$ elicited the largest response magnitude, so it was chosen as the standard for neurons with oral cavity receptive fields and applied twice in the stimulation sequence to monitor the stability of the preparation ${ }^{39}$. Stimuli for the epiglottis were applied as follows: $\mathrm{KCl}$, $\mathrm{NH}_{4} \mathrm{Cl}$, distilled water, $\mathrm{HCl}, \mathrm{KCl}$. For stimulation of the epiglottis $\mathrm{KCl}$ was chosen as the standard based on previous recordings from SLN fibers and NTS neurons with epiglottal receptive fields ${ }^{12,58,62}$. At least 2 min elapsed between stimulations to prevent cumulative adaptation ${ }^{57}$, and for $48 \%$ of the neurons the total sequence of stimuli was repeated.

In addition to the application of chemical stimuli and the subsequent $40 \mathrm{ml}$ of rinse, $10 \mathrm{ml}$ of rinse solution at oral cavity-epiglottis temperature was applied from a $10 \mathrm{ml}$ syringe during the stimulation sequence before each application of the chemical standard. These $10 \mathrm{ml}$ rinses were used as a control to determine those portions of the evoked responses due only to the mechanical effects of flowing a solution over the receptor areas.

Thermal. Thermal stimulation was accomplished 
by applying $10 \mathrm{ml}$ of cool or warm rinse solutions (water for the oral cavity, $0.154 \mathrm{M} \mathrm{NaCl}$ for the epiglottis) from $10 \mathrm{ml}$ syringes fitted with 19-gauge needles. The temperatures of the rinse solutions were 25,33 , 38 , and $42^{\circ} \mathrm{C}$. The rinse solutions were delivered in the following steps: tongue-epiglottis temperature $\left(33{ }^{\circ} \mathrm{C}\right.$ ) to $38^{\circ} \mathrm{C}, 38$ to $25^{\circ} \mathrm{C}, 25$ to $38^{\circ} \mathrm{C}, 38$ to $42^{\circ} \mathrm{C}$, 42 to $38^{\circ} \mathrm{C}$. When a neuron received a second presentation of the thermal stimuli the order of presentation was reversed. In order to control for the mechanical effects of flow, the response to rinse solutions at tongue-epiglottis temperature was determined as noted above and subtracted from the responses produced by the different temperature rinses. The thermal stimulation sequence was repeated for $44 \%$ of the isolated cells.

Mechanical. Mechanical stimulation consisted of a moving glass probe (glass rod, $5 \mathrm{~mm}$ tip diameter), a moving soft brush, and punctate stim ' ation applied using a hand-held, modified Grass strain gauge (circular brass stimulating surface, $5 \mathrm{~mm}$ in diameter). The strain gauge was connected to an amplifier and chart recorder which provided a permanent record of stimulation pressure. Punctate stimulation ranged from 1 to $7 \pm 0.2 \mathrm{~g}$ and was applied for 4 to $10 \mathrm{~s}$. Over $85 \%$ of the neurons receiver repeated applications of the moving mechanical stimuli and punctate stimulation was applied at least twice for $55 \%$ of the neurons.

\section{Histology}

Following application of the different stimulus moialities, the location of the recording site was marked by passing $35 \mu \mathrm{A} \mathrm{DC}$ for $3-5 \mathrm{~s}$ through the electrode. This produced a small lesion (35- $45 \mu \mathrm{m}$ diameter) at the recording site that did not impinge on adjacent electrode tracks which were $300 \mu \mathrm{m}$ distant. At the end of the experiment the animal was given an overdose of pentobarbital and perfused through the carotid arteries with buffered saline followed by $10 \%$ buffered formalin. The brainstem from obex to the inferior colliculus was removed and stored in $30 \%$ sucrose-formalin until sectioned. The brain was cut coronally in 40 or $50 \mu \mathrm{m}$ sections and mc anted on slides coated with chrom-alum. The tissue was stained using the Auletta method ${ }^{65}$, and recording sites were marked on standard drawings of the lamb brainstem.

\section{Data analysis}

Recorded neural impulses were converted into standard electrical impulses using a window discriminator. Intervals between pulses in milliseconds were measured with a microcomputer ${ }^{6}$, and this information was then converted to frequencies (impulses/s). In order to analyze only that portion of responses due to a stimulus, mean spontaneous frequency was subtracted from evoked responses. The spontaneous frequency was calculated by averaging the $5 \mathrm{~s}$ immediately preceding a stimulation and subtracting this mean from the response evoked by that stimulation. Furthermore, because many neurons responded to mechanical stimulation, the mean response frequency due to the mechanical effects of flowing a stimulus solution over the receptive field aiso was subtracted from the total response. The mean response frequency resulting from the mechanical effects of stimulus flow was determined by averaging the responses across the two $10 \mathrm{ml}$ rinses which preceded applications of the chemical standards during the chemical stimulation sequence. Therefore, the responses analyzed represent responses only to the individual stimulus modalities. For those neurons which received repeated presentations of the stimuli, the response was the average of these repeated presentations.

Previous investigations of lamb NTS neurons have shown that the responses to some chemical stimuli do not attain peak frequency until some time following the onset of stimulation ${ }^{62}$. Therefore, the presence of a response to chemical stimulation was defined as a difference in average adjusted response frequency (spontaneous frequency and response due to flow subtracted) during any 5 sequential seconds of the stimulation period greater than the mean \pm 2 S.D. of the spontaneous activity. This criterion permits the analysis of responses which show an increase or decrease in response frequency with time.

A response to thermal stimulation was defined as an increase or decrease in the adjusted response frequency during any 5 sequential seconds of the stimulation period greater than the mean spontaneous activity \pm 2 S.D.

A neuron was considered responsive to a moving mechanical stimulus if its maximum $1 \mathrm{~s}$ adjusted response (spontaneous rate subtracted) during the stimulation period was greater than the mean spontaneous activity \pm 2 S.D. The presence of a response 

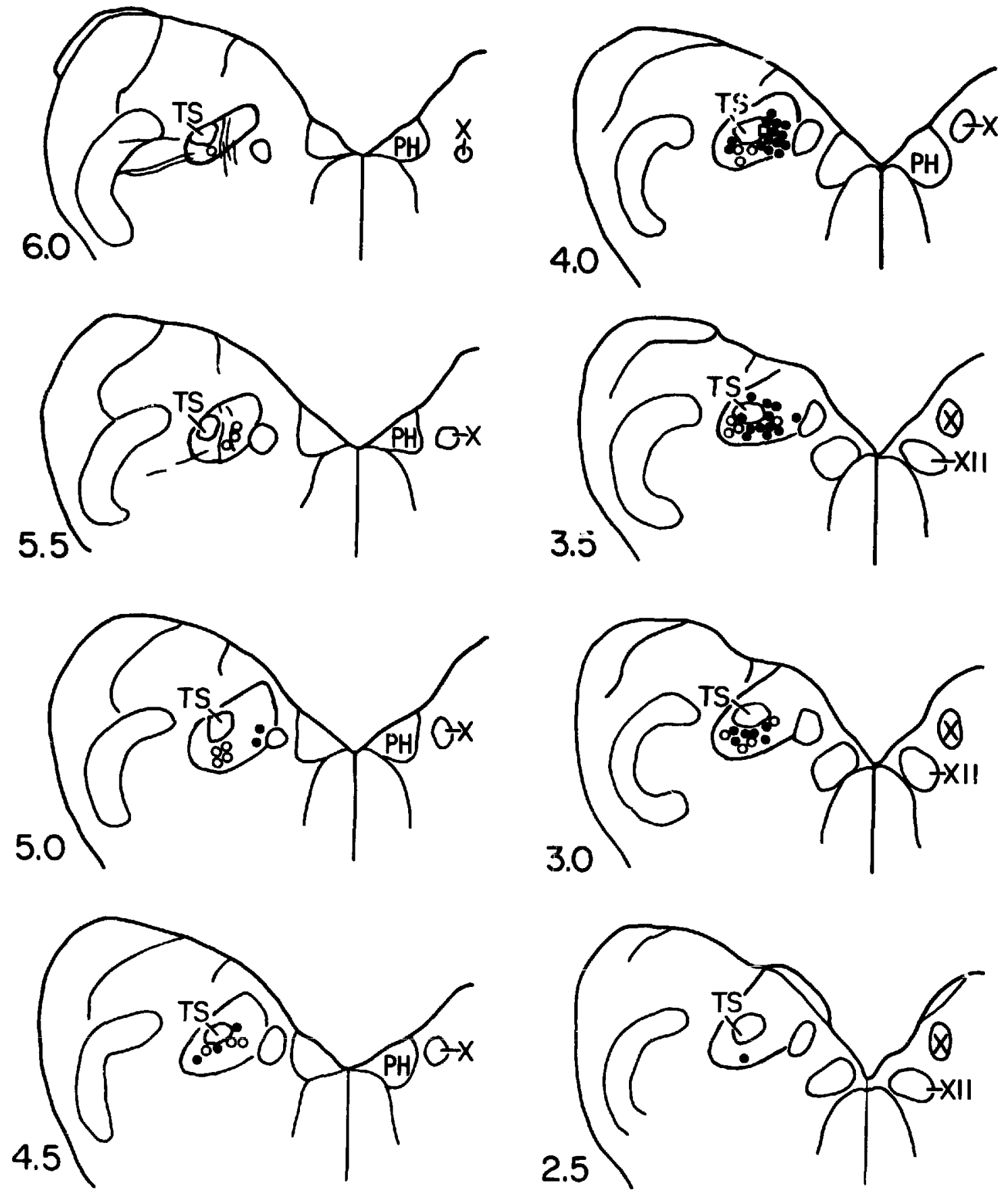

Fig. 1. Anatomical reconstructions of recording sites in the lamb NTS. Open circles and filled circles represent recording sites of OC and $E$ neurons, respectively. One neuron responsive to both $\mathrm{OC}$ and $\mathrm{E}$ stimulation is represented by the open square in the top right schematic. Although some overlap between recording sites of $\mathrm{OC}$ and $\mathrm{E}$ neurons was observed, the mean locations of these two groups of neurons were significantly different. Distances rostral to obex (in mm) of each representative brainstem section are given at the lower left of each section. PH, prepositus hypoglossi; TS, tractus solitarius; X, dorsal motor nucleus of the vagus; XII, hypoglossal nucleus. 
to punctate stimulation was defined as a increase or decrease in the first $1 \mathrm{~s}$ of the stimulation period greater than the mean \pm 2 S.D. of the spontaneous activity.

\section{RESULTS}

\section{Anatomical organization}

We recorded the responses of 63 single neurons responsive to stimulation of the caudal oral cavity or epiglottis. Two of these neurons were located in the ventrolateral reticular formation near the nucleus ambiguus and were omitted from the analysis. The locations of recording sites of the remaining 61 single neurons are shown in Fig. 1. Neurons were located in the intermediate region of the NTS between 2.4-5.9 mm rostral to obex, $2.7-4.7 \mathrm{~mm}$ lateral to the midline, and $1.7-3.8 \mathrm{~mm}$ ventral to the brainstem surface. The locations of neurons with receptive fields in the oral cavity and those with receptive fields on the epiglottis are indicated by different symbols in Fig. 1. It is apparent that although there was some overlap, neurons with caudal oral cavity receptive fields (open circles) tended to be located more rostral, lateral and ventral in the NTS than neurons with receptive fields located on the epiglottis (filled circles). Neurons with receptive fields in the caudal oral cavity (OC neurons) were located between $2.5-5.9 \mathrm{~mm}$ anterior to obex, 3.2-4.8 mm lateral to the midline and 2.0-3.8 $\mathrm{mm}$ ventral to the brainstem surface. Neurons with receptive fields on the epiglottis ( $E$ neurons) were located between 2.4-5.1 mm rostral to obex, 2.7-4.7 $\mathrm{mm}$ lateral to the midline and $1.7-3.7 \mathrm{~mm}$ ventral to the surface of the brainstem. The mean recording sites of the different groups of neurons are given in Table I. A comparison of the mean recording sites of $O C$ and $E$ neurons indicated that the locations of these two groups were significantly different in all three coordinates (two-tailed $t$-test: anterior-posterior, $t=2.62, P=0.01$; medial-lateral, $t=2.69, P=$ 0.009 ; dorsal-ventral, $t=4.14, P=0.0001$ ).

\section{TABLE I}

Mean recording sites and standard errors (in $\mathrm{mm}$ ) for neurons isolated in the lamb NTS

\begin{tabular}{llll}
\hline & All neurons & OC neurons & Eneurons \\
\hline Anterior to obex & $3.9 \pm 0.1$ & $4.2 \pm 0.2$ & $3.7 \pm 0.1$ \\
Lateral to midline & $3.7 \pm 0.1$ & $3.9 \pm 0.1$ & $3.6 \pm 0.1$ \\
Ventral to surface & $2.6 \pm 0.1$ & $3.0 \pm 0.1$ & $2.5 \pm 0.1$ \\
\hline
\end{tabular}

In addition to the neurons responsive to either oral cavity or epiglottal stimulation, one neuron had receptive fields in both receptor areas (open square, $4.0 \mathrm{~mm}$ rostral to obex in Fig. 1). This neuron had receptive fields on the epiglottis and caudal soft palate and was located in an area of the NTS where the largest numbers of $E$ neurons (14/39) were isolated. Furthermore, this region of the NTS was the area in which the recording sites of $O C$ neurons were intermingled among the recording sites of $E$ neurons (the schematic drawings from $3.0-4.5 \mathrm{~mm}$ rostral to obex in Fig. 1).

\section{General response characteristics}

Of the 61 NTS neurons 22 had receptive fields located in the caudal oral cavity. Based on the location of the receptive field there were 3 different types of OC neurons. Six OC neurons had their receptive field restricted to the caudal tongue, 6 neurons responded only when the caudal palate was stimulated and 10 neurons had two receptive fields, one on the tongue and one on the palate. An example of an OC neuron with both tongue and palate receptive fields is shown in Fig. 2. This neuron responded to both mechanical and thermal stimuli. The locations of this neuron's receptive fields can be seen in the two schematic drawings. Stimulation of the palate resulted in a decrease in the ongoing neural activity, whereas stimulation of the tongue produced increases in response frequency. This antagonism produced by stimulation of the two receptive fields was observed in two of the 10 OC neurons with receptive fields on

Fig. 2. Oscillograph tracings of responses from an NTS neuron which had receptive fields located opposite each other on the tongue and palate. This neuron responded to both mechanical and thermal stimuli applied to either receptive field. Stimulation of the tongue with either stimulus modality produced an increase in activity whereas stimulation of the palate decreased ongoing activity. The locations of this neuron's receptive fields are shown in the two, inset schematic drawings. The solid lines beneath each recording denote periods of stimulation. The time bar applies to all recordings. 
palate
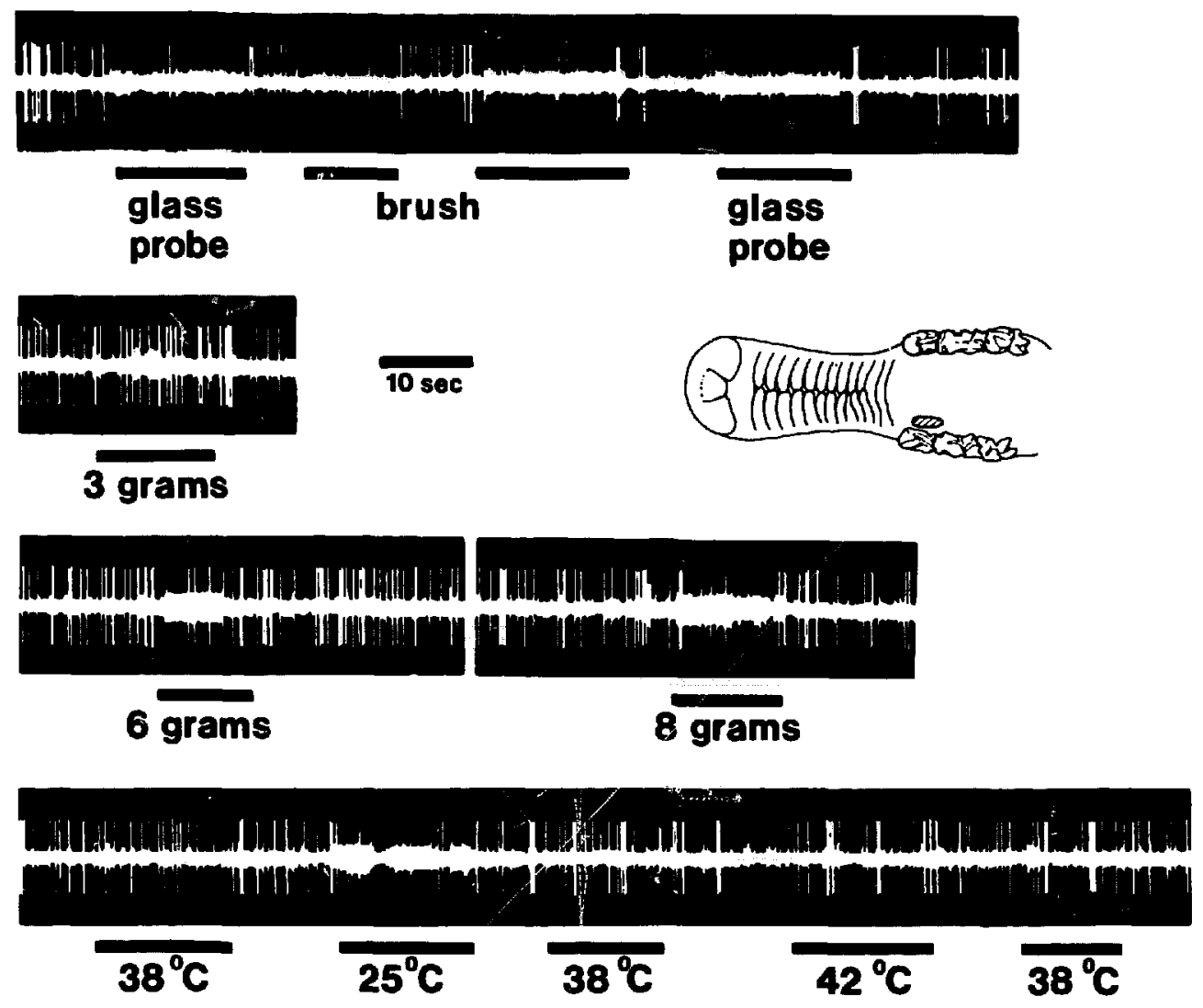

\section{TONGUE}
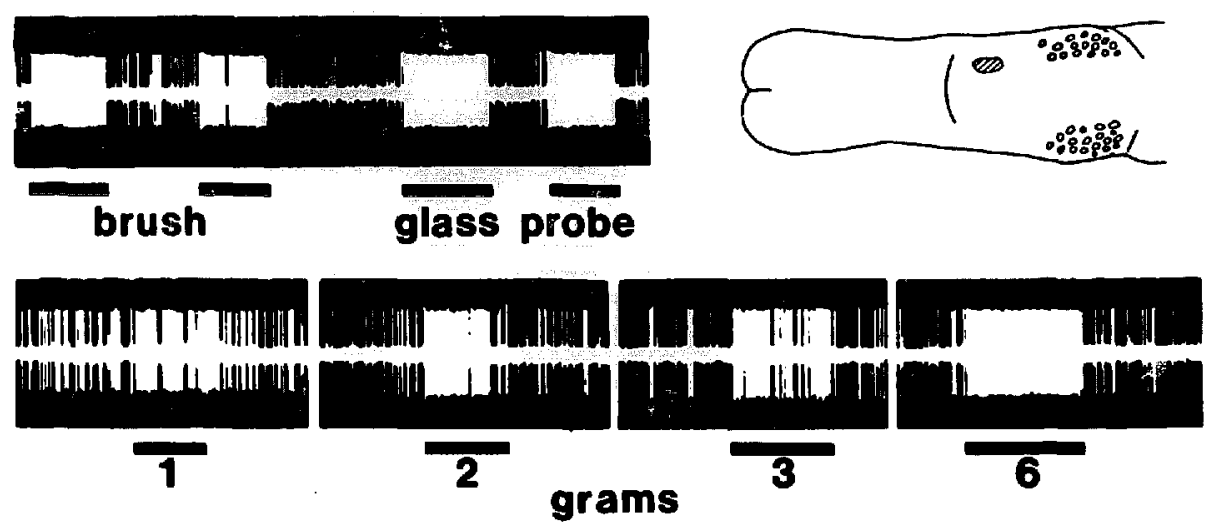

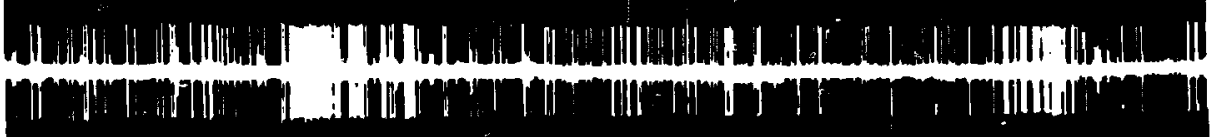

$$
\begin{array}{lllll}
\overline{38} 8^{\circ} \mathrm{C} & \overline{25} 5^{\circ} \mathrm{C} & \overline{38}{ }^{\circ} \mathrm{C} & \overline{42}{ }^{\circ} \mathrm{C} & \overline{38} 8^{\circ} \mathrm{C}
\end{array}
$$




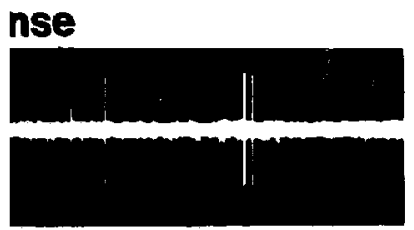

I

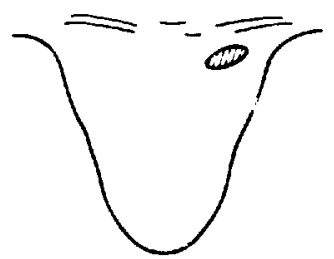

\section{$5 \mathrm{M} \mathrm{KCl}$}

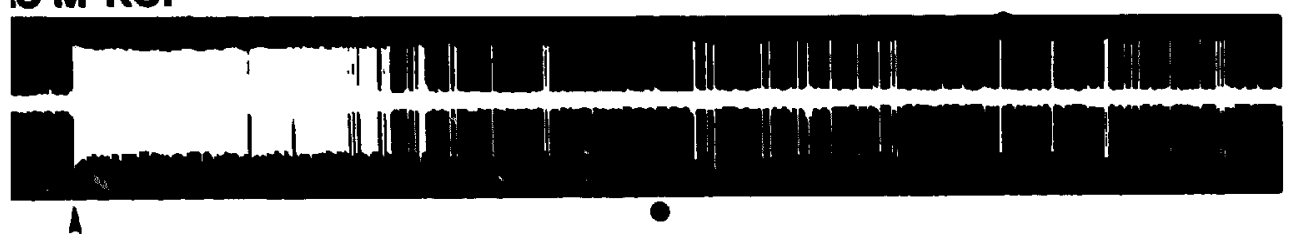

\section{$.5 \mathrm{M} \mathrm{NH}_{4} \mathrm{Cl}$}

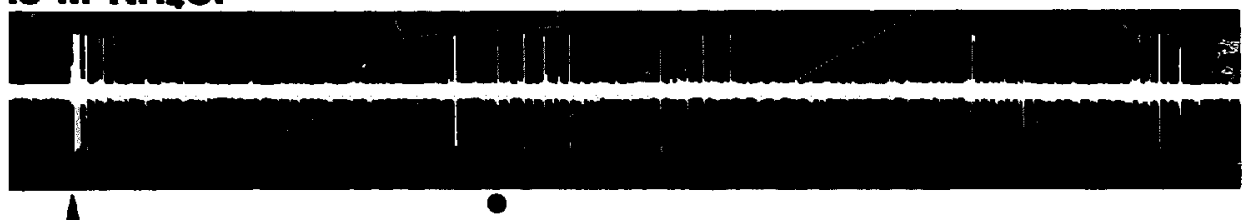

\section{istilled water}

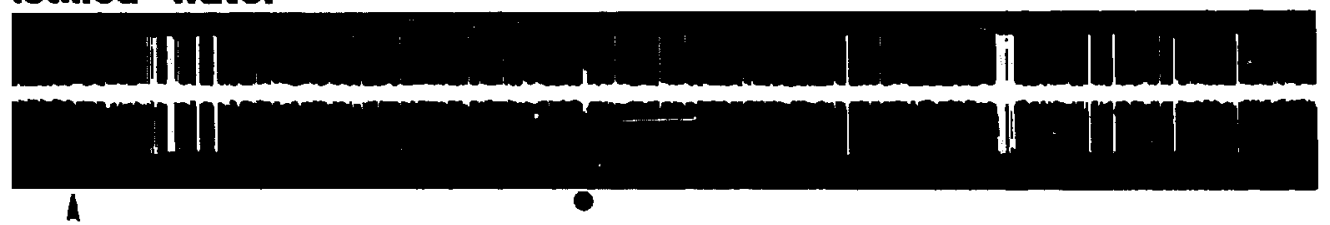

\section{$1.01 \mathrm{~N} \mathrm{HCl}$}

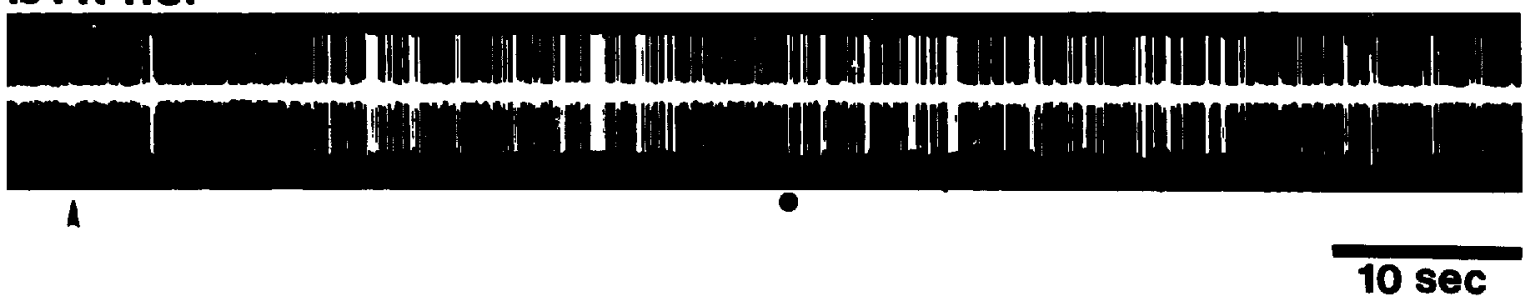

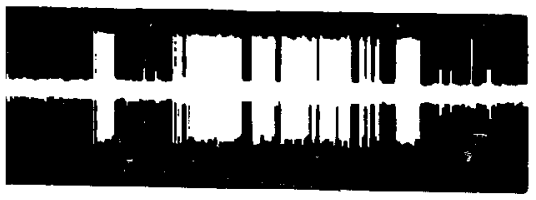

glass probe

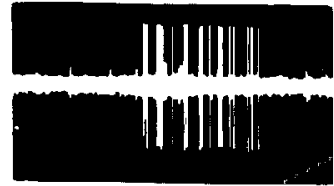

1
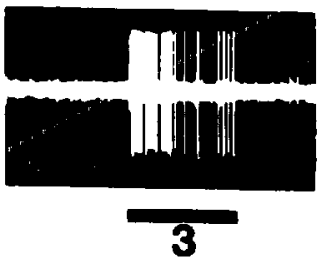

grams
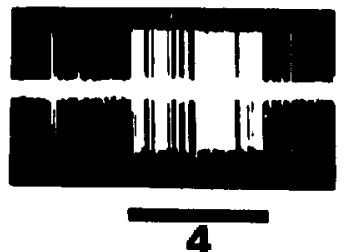

Fig. 3. Oscillograph tracings of responses from an NTS neuron whose receptive field was located on the laryngeal surface of the epiglottis. This neuron responded to both chemical and mechanical stimuli. Onsets of the chemical stimuli are denoted by arrows; onsets of the poststimulus rinses by filled circles. Periods of mechanical stimulation are indicated by solid lines. The location of this neuron's receptive field is shown in the schematic drawing at the upper right. The time bar applies to all recordings. 
both the tongue and palate. The remaining 8 neurons showed complementary (both excitatory) responses.

Thirty-eight of the NTS neurons had receptive fields located on the epiglottis. An example of this group of neurons is shown in Fig. 3. This neuron responded to chemical and mechanical stimulation of the receptive field shown in the schematic drawing at the upper right of the figure.

The spontaneous rates of both OC and $E$ neurons were generally quite slow, with the mean spontaneous activity ranging from 0 to $15.8 \mathrm{impulses} / \mathrm{s}$. Nine neurons were not spontaneously active and a majority of the remaining neurons had mean spontaneous rates of less than $1.5 \mathrm{impulse} / \mathrm{s}\left(31 / 5^{\circ} \mathrm{z}\right)$. There was no significant difference in the spontaneous activity of OC neurons ( $\bar{x}=1.8 \pm 0.65$ S.E.M. $)$ and $E$ neurons $(\bar{x}=2.7 \pm 0.64)$.

The NTS neurons isolated in the present study frequently responded to more than one of the 3 stimulus modalities. Fig. 4A shows that over $68 \%$ of the NTS neurons responded to two or all 3 stimulus modalities. The number of stimulus modalities which neurons responded to was somewhat dependent upon the location of their receptive fields. In Fig. 5A the percentage of $\mathrm{OC}$ neurons which responded to only one, two or all 3 of the stimulus modalities is compared with the percentage of $E$ neurons in each category. A larger percentage of $\mathrm{OC}$ than $E$ neurons
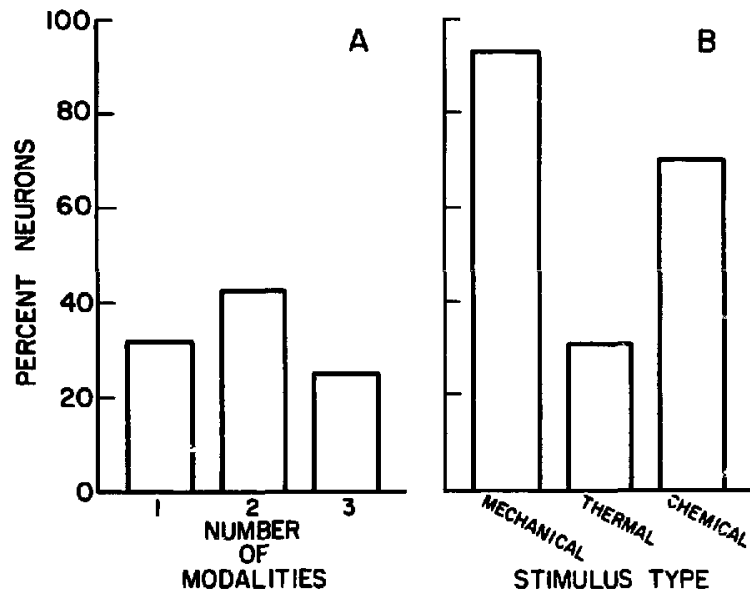

Fig. 4. A: percentage of all neurons which responded to only one, two or all 3 of the stimulus modalities. Sixty-eight percent of NTS neurons responded to more than one of the 3 stimulus modalities used in the current study. B: percentage of all neurons which responded to mechanical, thermal or chemical stimuli. responded to just a single stimulus modality. In all cases the modality-specific $O C$ neurons responded to mechanical stimuli, while most modality specific $\mathbf{E}$ neurons responded to chemical stimuli. More $\mathrm{E}$ than $O C$ neurons responded to two of the stimulus modalities. The modality combination most frequently observed for $\mathrm{E}$ neurons responsive to two stimulus modalities was chemical and mechanical (95\%), whereas a mechanical and thermal combination was observed most often in OC neurons. The number of $O C$ and $E$ neurons which responded to all 3 of the stimulus modalities was quite similar. A comparison of the mean number of stimulus modalities which elicited activity in $\mathrm{OC}(\bar{x}=1.7 \pm 0.17)$ and $\mathrm{E}(\bar{x}=2.1$ \pm 0.11 ) reurons demonstrated that $O C$ neurons responded to a significantly smaller number of the 3 modalities than $\mathrm{E}$ neurons (two-tailed $\boldsymbol{t}$-test, $\boldsymbol{t}=\mathbf{2 . 0}$, $P<0.05$ ).

Fig. 4B shows the percentage of NTS neurons which responded to the different stimulus types. Mechanical stimulation was the most effective eliciting responses from $91 \%$ of the neurons. Chemical stimuli were also quite effective, while thermal stimuli were relatively ineffective. As shown in Fig. 5B, the response to an individual stimulus type was also dependent upon the receptor area from which a neuron received sensory input. Mechanical stimulation was an effective stimulus for both $\mathrm{OC}$ and $\mathrm{E}$ neurons. Every OC neuron and $85 \%$ of the $E$ neurons responded to at least a moving mechanical stimulus. Although less effective than mechanical stimuli, thermal stimuli elicited responses in about the same percentage of $O C$ and $E$ neurons (32 and 29\%, respectively). The major difference between $O C$ and $E$ neurons was in the number of cells which responded to chemical stimuli. A significantly smaller number of $O C$ than $E$ neurons showed responses to chemical stimuli (Fischer-Exact test, $\left.x^{2}=31.23, P<0.0001\right)$.

\section{Responses to mechanical stimuli}

Mechanical stimuli were the most effective of the 3 stimulus modalities. Fig. $6 \mathrm{~A}$ shows that most mechanosensitive neurons responded to moving and punctate stimuli. Responses to both types of mechanical stimulation were observed in 55\% of the OC neurons and almost $80 \%$ of the E neurons. Only $22 \%$ of the NTS neurons responded just to a moving stimulus and no neurons responded only to punctate stimula- 

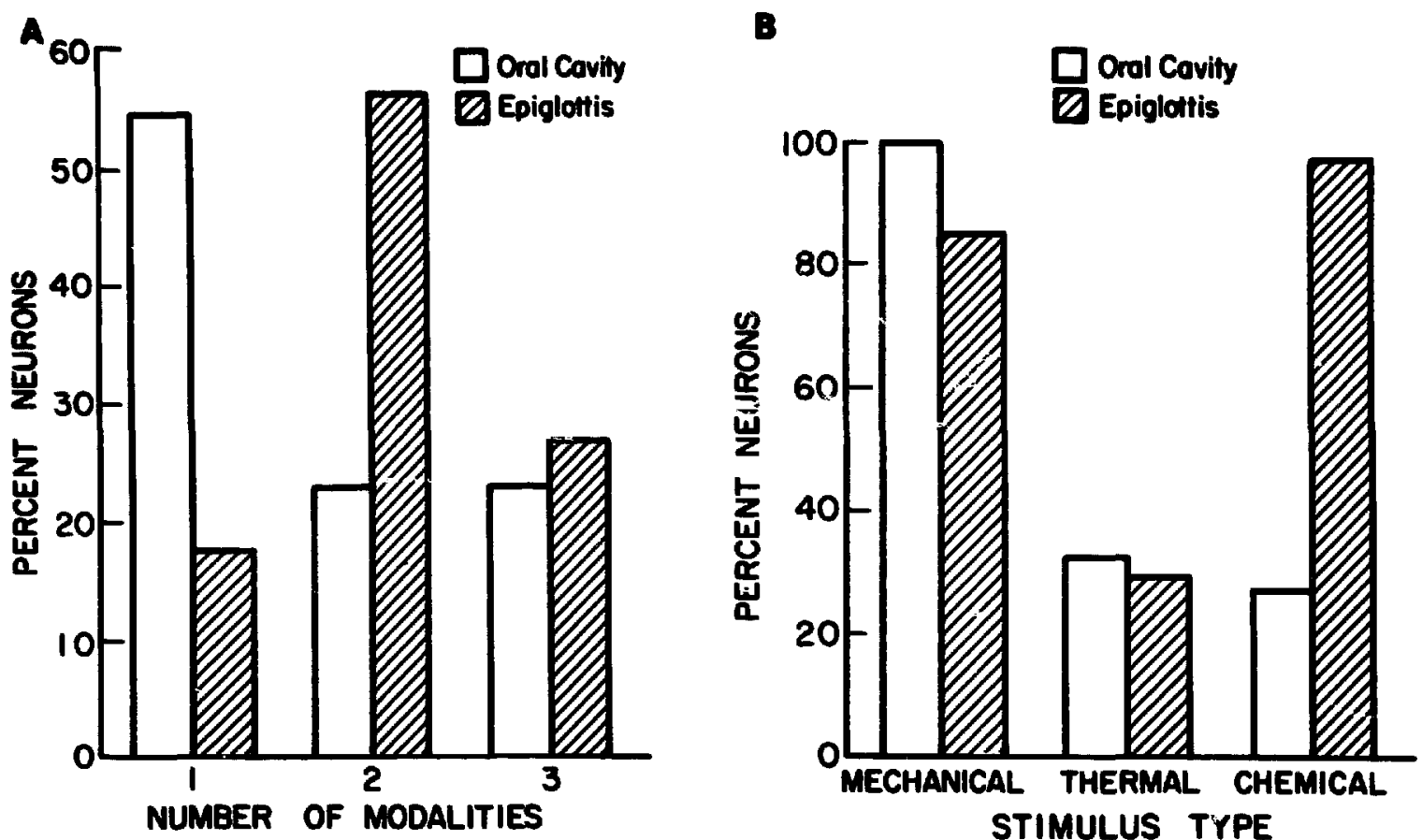

Fig. 5. A: a comparison of the percentage of oral cavity and epiglottal neurons which responded to one, two or all 3 of the stimulus modalities. The majority of $O C$ neurons responded to only one of the stimulus modalities whereas most $E$ neurons responded to two or all 3. B: comparison of the percentage of oral cavity and epiglottal neurons which responded to different types of stimuli. While mechanical and thermal stimuli were effective for both $\mathrm{OC}$ and $\mathrm{E}$ neurons, there was a large difference in the effectiveness of chemical stimuli for these two groups of neurons. Note that the ordinates of $A$ and $B$ are scaled differently.
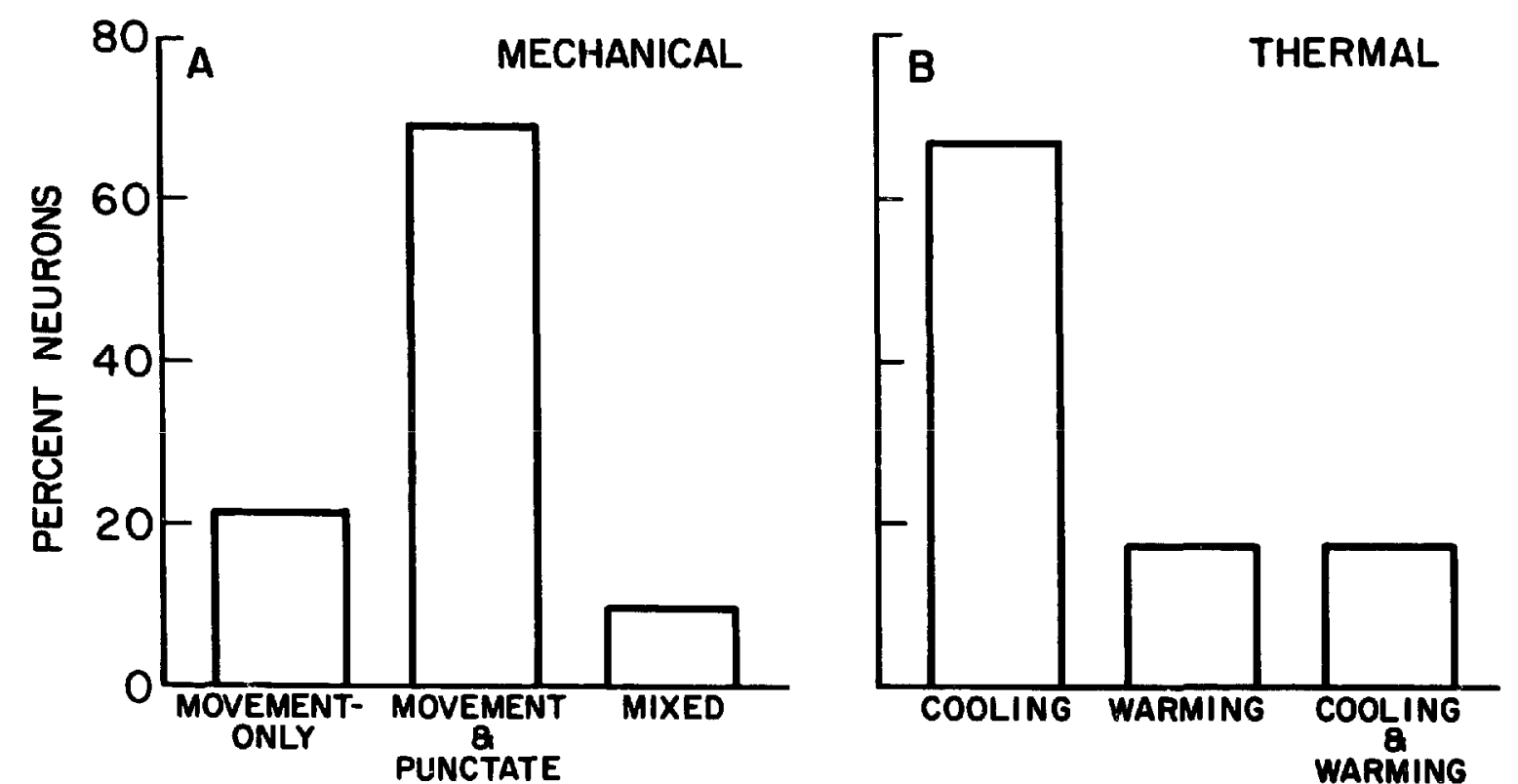

Fig. 6. A: percentage of mechancsensitive neurons which responded only to a moving stimulus or to both a moving and punctate stimulus. Some neurons with both a tongue and a palate receptive field had a mixed response in that they responded to both types of mechanical stimuli on one of the receptive fields, but only to a moving stimulus on the other. B: percentage of thermosensitive neurons which responded to cooling, warming or both cooling and warming stimuli. 
tion. The numbers of $\mathrm{OC}$ and $\mathrm{E}$ neurons which responded only to a moving stimulus were about equal. Neurons which showed a mixed response to the two types of mechanical stimuli comprised a subset of the neurons which had both tongue and palate receptive fields. These neurons would respond to stimulation of both fields with a moving mechanical stimulus, but a punctate stimulus evoked a response only when it was applied to one of the two fields. Of the 11 neurons with two receptive fields, 5 showed this mixed type of response.

The range and mean $1 \mathrm{~s}$ maximum responses to moving mecharical stimuli are shown in Table II. For OC neurons the brush or glass probe were about equally effective stimuli while stimulating the epiglottis with a soft brush was slightly more effective than stimulation with a glass probe.

For both $O C$ and $E$ neurons punctate stimuli between 2 and $7 \mathrm{~g}$ pressure were quite effective. All of the neurons responsive to punctate stimuli responded to at least one stimulus within this range and $90 \%$ responded to all 6 . Stimulation at $1 \mathrm{~g}$ was less effective in eliciting responses with a greater percentage of $E$ (70\%) than OC (58\%) mechanosensitive neurons responding to this strength of stimulation. The mean response frequencies produced by different strengths of punctate mechanical stimulation are shown in Fig. 7 for $O C$ and $E$ neurons. This figure shows that across the population of NTS neurons, the response frequencies produced by punctate mechanical stimulation of the epiglottis were always greater than those observed to an equivalent magnitude of stimulation applied to the OC. A comparison of the responses of these two groups of neurons across all levels of stimulation demonstrated that $E$ neurons had a significantly larger response than $O C$ neurons $(F(1,45)=9.97$, $P=0.003$ ). Also evident in Fig. 7 is that both OC and $E$ neurons showed relatively small increases in response frequency with increases in stimulus strength.

\section{TABLE II}

Range (impulses/s) and mean maximum I s response (impulses/s) to moving mechanical stimuli

\begin{tabular}{lcc}
\hline & OC neurons & Eneurons \\
\hline Glass probe & $2.0-68$ & $4.0-84$ \\
& $20.2 \pm 2.5$ S.E.M. & $26.1 \pm 3.4$ \\
Brush & $2.0-63$ & $4.0-120$ \\
& $21.3 \pm 2.8$ & $31.6 \pm 5.4$ \\
\hline
\end{tabular}

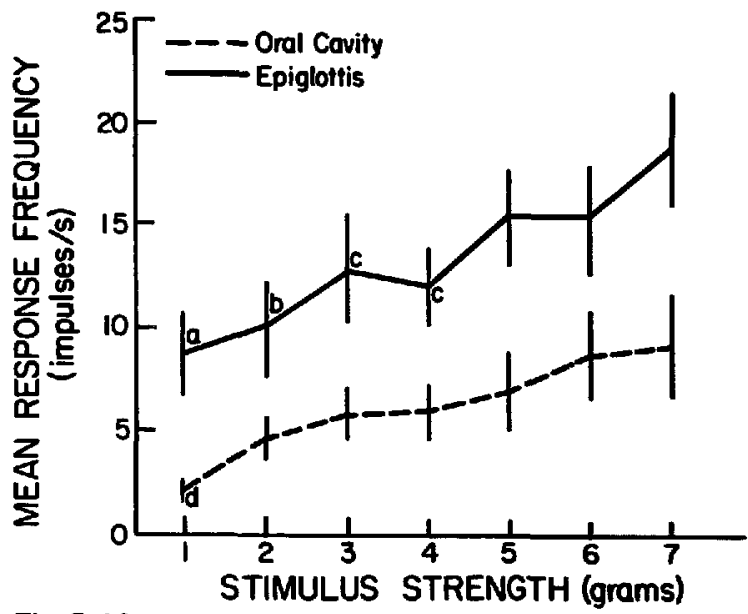

Fig. 7. Mean response frequencies and standard errors of the mean of oral cavity and epiglottal neurons to the different intensities of punctate mechanical stimulation. Results of a pairwise comparison between the means within each group are coded by the letters adjacent to the mean values (ANOVA for repeated samples. Tukey combined with Bonforoni for pairwise comparisons, $P<\mathbf{0 . 0 5}$ ). a, significantly different from epiglottal means at 4, 5, 6 and $7 \mathrm{~g}$; b, significantly different from 5 , 6 and 7 means; $c$, significantly different from $7 \mathrm{~g}$ mean; d, significantly different from $7 \mathrm{~g}$ oral cavity mean. Note that the mean responses of $E$ neurons were always larger than $O C$ neurons for a given stimulus strength.

This was particularly true for $O C$ neurons, where a significant increase in the response frequency was only observed between the weakest and strongest strengths of punctate mechanical stimulation. As noted above OC neurons also showed relatively little discrimination to different strengths of a moving stimulus as is evident by the similar mean responses produced by stimulation with either the glass probe or brush (Table II). As a group, E neurons showed slightly more sensitivity to increases in punctate mechanical stimulation (Fig. 7). However, like OC reurons, increases in stimulus strength required to produce a significant increase in response frequency of $E$ neurons were relatively large, and no significant differences were observed between stimulus strengths of $5 \mathrm{~g}$ or greater.

\section{Responses to chemical stimuli}

In the area of the NTS sampled in the present study, applications of chemical stimuli were much more effective in eliciting responses when placed on the laryngeal surface of the epiglottis than either the tongue $\sigma_{\text {: }}$ the palate. Only one $E$ neuron did not respond to chemical solutions. Table II! presents the 
mean response magnitudes produced by the different chemical stimuli in $O C$ and $E$ neurons. For $E$ neurons $\mathrm{KCl}$ was the most effective chemical stimulus, eliciting responses in all chemosensitive $\mathrm{E}$ neurons and producing the highest response frequency. $\mathrm{HCl}$, distilled water and $\mathrm{NH}_{4} \mathrm{Cl}$ also were quite effective, producing responses in 91,89 and $83 \%$ of the $E$ neurons, respectively. Of the chemosensitive $E$ neurons four responded exclusively to chemical stimuli.

Chemical stimuli delivered to the oral cavity were relatively ineffective for the $\mathrm{OC}$ neurons in the region of the NTS sampled in the present study. Only 6 neurons responded to chemical stimuli. Three of these neurons had receptive fields on the tongue and two had palate receptive fields. The one remaining neuron had both tongue and palate receptive fields, but responded to chemical stimuli only when they were placed on the caudal tongue. All receptive fields of $O C$ neurons responsive to chemical stimulation of the tongue were iocated over the vallate papillae, while receptive fields on the palate were located on the soft palate. The most effective stimulus for $\mathrm{OC}$ neurons was $\mathrm{NH}_{4} \mathrm{Cl}$ which produced responses in $100 \%$ of the chemosensitive neurons. Stimulation with $\mathrm{KCl}$ and $\mathrm{HCl}$ produced responses in $83 \%$ of the chemosensitive neurons and $0.15 \mathrm{M} \mathrm{NaCl}$ was the least effective stimulus generating responses in only two of the 6 cells. $\mathrm{NH}_{4} \mathrm{Cl}$ also elicited the largest mean response magnitude of the four stimuli, followed by $\mathrm{KCl}, \mathrm{NaCl}$ and $\mathrm{HCl}$ (Table III). $\mathrm{OC}$ neurons which responded to chemical stimuli were always responsive to at least one of the other stimulus modalities.

\section{Responses to thermal stimuli}

Of the 3 stimulus modalities tested in the present study, thermal stimuli were the least effective for both $O C$ and $E$ neurons. Less than one-third of the

\section{TABLE III}

Mean response freqiaency (impulses/s) produced by chemical stimuli

\begin{tabular}{lcr}
\hline & OC neurons & E neurons \\
\hline $\mathrm{KCl}$ & $21.5 \pm 11.4$ S.E.M. & $32.3 \pm 3.9$ \\
$\mathrm{NH}_{4} \mathrm{Cl}$ & $24.2 \pm 13.7$ & $5.9 \pm 1.5$ \\
$\mathrm{HCl}$ & $7.4 \pm 3.2$ & $19.9 \pm 2.6$ \\
Distilled water & - & $14.8 \pm 2.1$ \\
$\mathrm{NaCl}$ & $14.9 \pm 5.5$ & - \\
\hline
\end{tabular}

isolated cells responded to this stimulus modality (see Fig. 4B). Fig. 6B shows that the majority of the thermosensitive neurons responded to cooling. Cooling was effective for both $\mathrm{OC}$ and $\mathrm{E}$ neurons eliciting responses in 63 and $70 \%$ of the thermosensitive cells, respectively. A temperature drop from $38-25^{\circ} \mathrm{C}$ produced a mean response frequency of $11.4 \pm 4.2$ impulses/s in thermosensitive OC neurons and $9.9 \pm$ 2.6 impulses/s in E neurons. A smaller reduction in temperature from 42 to $38^{\circ} \mathrm{C}$ evoked mean response frequencies of $8.55 \pm 3.1$ and $4.0 \pm 2.0 \mathrm{impulses} / \mathrm{s}$ in $O C$ and $E$ neurons, respectively.

Also shown in Fig. 6B is that applications of warm stimuli were relatively ineffective. Only $17 \%$ of the thermosensitive neurons responded exclusively to warming. A temperature increase from 38 to $42{ }^{\circ} \mathrm{C}$ was the most effective warming stimulus and produced a mean response frequency of $4.6 \pm 1.8 \mathrm{impul}-$ ses/s in these neurons. Like neurons which responded to warming, neurons which responded to both cooling and warming were observed infrequently (17\%). All neurons which responded to both thermal stimuli exhibited a larger response frequency when the receptive field was cooled than when warmed.

\section{Receptive fields}

The receptive fields of neurons which responded to oral cavity stimulation were located in the ipsilateral oral cavity or straddled the midline. The locations of the receptive fields for each of the $22 \mathrm{OC}$ neurons are shown in Fig. 8. The receptive fields of the $6 \mathrm{OC}$ neurons that responded only to stimulation of the caudal tongue are shown in the schematic drawing at the top of the figure. The receptive fields of these neurons were for the most part clustered around rostral vallate papillae and were of moderate size. The locations of the receptive fields for the 6 of the OC neurons which had receptive fields restricted to the caudal palate are shown in the second schematic drawing of Fig. 8. Most of the receptive fields were located on the caudal hard palate or at the border of the hard and soft palate. The receptive fields of these neurons tended to be larger than neurons with receptive fields resiricted to the tongue. The receptive field locations for the remaining $10 \mathrm{OC}$ neurons which responded to stimulation of both the caudal palate and caudal tongue are shown in the bottom four schematic drawings of Fig. 8. For comparison, the two receptive 
fields of each neuron are similarly shaded. It is evident in Fig. 8 that the location of a neuron's receptive field on the tongue was beneath its receptive field on the palate (see also Fig. 2). Furthermore, the size of the two receptive fields were usually quite similar.

All neurons which responded to stimulation of the epiglottis had receptive fields located on the ipsilateral laryngeal surface. The receptive fields were gener-

TONGUE-ONLY NEURONS

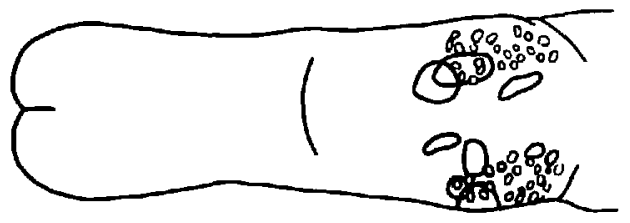

PALATE-ONLY NEURONS

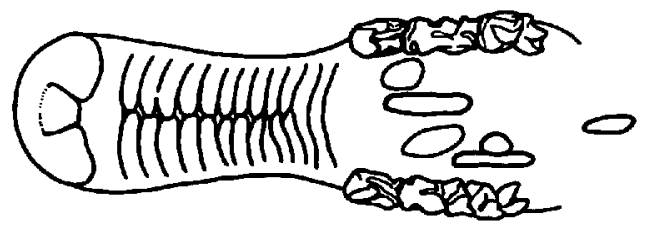

TONGUE a PALATE NEURONS
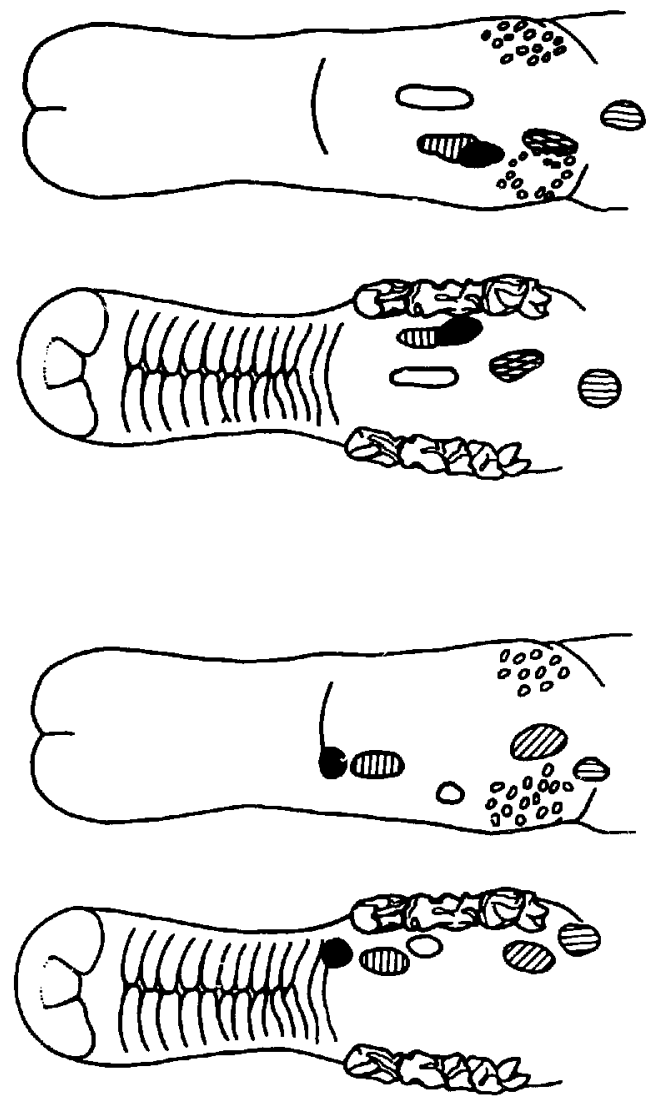

ally located near the base (see Fig. 3), and along the lateral edges of the epiglottis where the majority of epiglottal taste buds are located ${ }^{58}$. A wide range in the size of the receptive fields was observed. Some neurons had receptive fields which were about $1 \mathrm{~mm}^{2}$ while others covered almost the entire surface of the epiglottis.

\section{DISCUSSION}

\section{Multimodal neurons}

The large numbers of multimodal neurons observed in the NTS regions that we sampled suggest that these neurons play an important role in integration of sensory information from the oral cavity and epiglottis. Responses to more than one stimulus modality were particularly characteristic of $\mathbf{E}$ neurons; $88 \%$ of E neurons responded to more than one stimulus modality. The ability to integrate information is important for these neurons because the receptors located on the laryngeal surface of the epiglottis are important in the initiation of reflexes which prevent the aspiration of liquids and foods ${ }^{37}$. Detection of an intruding foreign object would be enhanced if information from all stimulus modalities could be utilized.

Our results confirm and extend previous investigations which have suggested that most NTS neurons with epiglottal receptive fields were responsive to chemical and moving mecharical stimuli ${ }^{62}$. However, multimodal neurons are not unique to regions of the NTS where E neurons were located. Investigations of more rostral, gustatory regions of the NTS in sheep, rats and frogs, and the analogous facial lobe in carp have reported that large numbers of chemosensitive neurons were also responsive to mechanical or

Fig. 8. Locations of receptive fields for 22 neurọs which responded to stimulation of the oral cavity. The top two schematic drawings show the receptive fields of $O C$ neurons which had responded to stimulation of only one receptor area. The bottom four drawings show the two receptive fields of each neuron which responded to stimulation of both the tongue and palate. Ten such neurons were isolated, and for clarity the receptive fields of 5 neurons have been mapped on each pair of schematic drawings. For comparison, the two receptive fields of an individual neuron have been similarly shaded. Note that these neurons usually had receptive fields on the tongue that were located beneath the receptive field on the palate. The border of the lamb hard and soft palate is located at approximately the level of the last molar. 
thermal stimuli or all 3 stimulus modalities ${ }^{10.23 .34}$, 35.44.46. Thus the multimodal nature of NTS neurons which receive chemosensory information îtom the epiglottis is similar to that observed in rostral NTS neurons which receive oral cavity chemosensory inputs.

The NTS neurons with oral cavity receptive fields tended to respond to a smaller number of stimulus modalities, as is reflected by the larger number of modality-specific OC neurons (see Fig. 5A). The vast majority of modality-specific $O C$ neurons responded only to mechanical stimuli. Behavioral and physiological studies have shown that mechanical stimulation of the caudal oral cavity and pharynx is more effective than chemical or thermal stimuli in eliciting oral cavity and upper airway reflex responses ${ }^{38.56 .66}$. Therefore it is perhaps not surprising that fewer $O C$ neurons responsive to both mechanical and chemical or mechanical and thermal stimuli were observed in the reflexogenic areas of the NTS which we sampled. More chemosensitive responses would be expected from neurons in more rostral NTS regions that receive input primarily from circumvallate papillae.

Although there were fewer multimodal OC than E neurons, almost $44 \%$ of the OC neurons did respond to more than one stimulus modality. One of the functions of the receptors of the oral cavity is to provide information on the position and size of stimuli which is important for such oral activities as mastication and swallowing. The information which is relayed from the oral cavity to the reflexogenic areas of the NTS could provide just such information.

\section{Mechanical, chemical and thermal responses}

Both the oral cavity and epiglottis are richly supplied with mechanoreceptors ${ }^{19}$. A number of studies have investigated responses of NTS neurons to mechanical stimulation; however, in most of these experiments the stimulation was restricted to brushing receptor areas with a probe, so the effects of a stationary stimulus could not be determined. In our investigation responses to punctate stimuli were observed less frequently and were of smaller magnitude in both groups of NTS neurons when compared to responses elicited by a moving stimulus. This finding is similar to that reported by Gentle ${ }^{20}$. He noted that the majority of neurons in the NTS of the chicken were less sensitive to sustained mechanical pressure ihan movement of the stimulus over the receptive field. Also, investigations of the reflex elicitation of swallowing have demonstrated that a moving mechanical stimulus was more effective than a stationary one for the elicitation of swallowing and the initiation of responses in the $\operatorname{SLN}^{59,60}$.

Increases in the strength of punctate stimulation produced only moderate increases in response frequency (Fig. 7). Similar results have been reported for some mechanosensitive neurons in the trigeminal nuclei $^{17}$ and superior colliculus ${ }^{32}$. The strong responses of NTS neurons to a moving stimulus and their failure to reflect much intensity information suggests that the mechanical information relayed to the NTS is important for the elicitation of reflex behavior rather than determining stimulus quality; to protect the upper airway only the presence of a stimulus is truly important. Qualitative mechanosensory information is probably relayed to forebrain structures by pathways other than the NTS.

However, it is possible that the apparent lack of intensity coding may reflect the limited range of stimulus pressures employed in the present study. Investigations of trigeminal neural responses to mechanical stimulation have shown that low threshold and wide dynamic range mechanosensitive neurons respond to stimulus forces of less than one gram ${ }^{1,50}$. Furthermore, wide dynamic range neurons in the trigeminal nucleus show large increases in response frequency when strong or noxious stimuli are applied. Applications of very weak or noxious mechanical stimuli may have revealed more intensity information precessing by NTS neurons.

Mechanical information from receptors in the oral cavity and epiglottis also appears to be important for the reflex control of muscle movements. For example, mechanical stimulation of the rat's tongue evokes bursts of efferent activity in hypoglossal nerve branches supplying the tongue protrusive and retractive muscles ${ }^{66}$. The reflexive tongue movements elicited by mechanical stimuli are probably important in the manipulation of a food bolus during mastication and the subsequent positioning of the bolus in preparation for swallowing. The subpopulation of OC neurons with two receptive fields positioned opposite each other on the tongue and palate would appear to be uniquely organized to take part in such a function; these neurons could provide precise infor- 
mation about the location of a stimulus within the oral cavity.

The response characteristics of NTS neurons to stimulation of the epiglottis with chemical stimuli were similar to those reported previously ${ }^{62}$. The responses of $O C$ neurons to chemical stimuli were comparable to those seen in the periphery of lamb and sheep ${ }^{39}$. In the lamb glossopharyngeal nerve, $0.5 \mathrm{M}$ $\mathrm{NH}_{4} \mathrm{Cl}$ produces the largest magnitude of response followed by $0.5 \mathrm{M} \mathrm{KCl}$. These two stimuli had the same order of effectiveness in NTS neurons. A concentration of $0.5 \mathrm{M} \mathrm{NaCl}$ was less effective in eliciting glossopharyngeal nerve responses than either of the other two salts. Therefore, the fact that only a few NTS neurons were responsive to the concentration used in the present study $(0.154 \mathrm{M})$ is not surprising. $\mathrm{HCl}$ was less effective than either $0.5 \mathrm{M} \mathrm{NH} \mathrm{NH}_{4} \mathrm{Cl}$ or $\mathrm{KCl}$ which was similar to results for the lamb glossopharyngeal nerve ${ }^{39}$.

It is perhaps surprising that more neurons responsive to chemical stimulation were not found in our investigation. Anatomical studies suggest that nerves from the caudal oral cavity project not only to the rostral gustatory portions of the NTS, but also send small projections to the areas of the NTS from which we sampled single neurons ${ }^{2,22,61}$. From our results it seems that the majority of chemosensory information from the caudal oral cavity is relayed to the more rostral areas of the NTS rather than the areas from which we recorded.

Compared to mechanical and chemical stimuli, thermal stimuli was not as effective in eliciting responses in our sample of NTS neurons. The region of the NTS which we sampled has been linked to swallowing ${ }^{13,26,28}$ in sheep and behavioral studies have suggested that temperature is a relatively ineffective stimulus for the elicitation of this reflex ${ }^{38,60}$. Thus, the ineffectiveness of thermal stimuli may reflect a weak input to this region from peripheral thermoreceptors. In contrast, investigations of gustatory neurons in the rostral NTS have reported that the majority of neurons responsive to taste stimuli were also sensitive to thermal stimuli ${ }^{34,48}$. In general, these latter studies of gustatory neurons did not look for celis which responded exclusively to thermal stimuli, so information as to their presence in other regions of the NTS is currently lacking. However, in the present study we found that like the rostral NTS, neurons which did respond to temperature generally responded to at least one of the other stimulus modalities. Thus it may be characteristic of the NTS that neurons which respond exclusively to thermal stimuli are relatively rare.

The most common response to thermal stimulation was observed to cooling the oral or epiglottal mucosa. The prevalence of neurons responsive to cooling rather than warming also has been observed in the NTS of other species ${ }^{20.34,48}$. Responses to thermal stimuli were occasionally observed in neurons which also responded to mechanical stimuli. This modality combination has previously been seen throughout the trigeminal nucleus ${ }^{51}$ and was a combination observed in the NTS of the chicken ${ }^{20}$.

As noted above, studies of more rostral gustatory regions of the NTS in rats suggest that thermal stimuli are quite effective, but our results indicate that it is a less effective stimulus for neurons with oral cavity or epiglottal receptive fields located in the more caudal regions of the NTS. Although thermal stimuli appear to be less effective stimuli for neurons in the caudal reflexogenic regions of the NTS some studies have suggested a role for thermal stimuli in certain laryngeal and tongue reflexes ${ }^{36,66}$. Whether the thermosensitive NTS neurons sampled in the present investigation are involved in these reflexes will require further investigation.

\section{Anatomical organization}

The recording sites of the neurons were located in NTS areas which receive afferent input from the caudal oral cavity and epiglottis. The sites from which the majority of $E$ neurons were isolated $(4.5-3.0 \mathrm{~mm}$ rostral to obex) correspond to regions of the lamh and sheep NTS which receive the largest number of SLN terminations ${ }^{13,27,61}$. This area of the NTS has been found to contain neurons which respond to stimulation of the epiglottis with clyemical or mechanical stimuli $^{62}$ and electrical stinulation of the SLN ${ }^{13.53}$. Furthermore, this area of the NTS has been implicated in the control of sivallowing and some oral and respiratory reflexes ${ }^{24,25,28,33,54}$.

Some overlap was observed in the recording sites of $\mathrm{OC}$ and $\mathrm{E}$ neurons. However, as a group $\mathrm{OC}$ neurons were located significantiy rostral, lateral and ventral to $E$ neurons, a finding similar to that reported in investigations of the reflexogenic areas of 
the cat NTS ${ }^{53}$. This separation of $O C$ and $E$ neurons reflects the underlying organization observed in anatomical studies. In areas of the lamb NTS where both caudal oral cavity and upper airway afferent fibers terminate, the sensory fibers from the upper airway tend to be located more medial and ventral in the nucleus $^{16.61}$. Furthermore, the small numbers of $O C$ neurons found in regions of the NTS where primarily E neurons were located confirms anatomical studies which have shown that the afferent nerves which innervate the caudal oral cavity send only minor projections to this area ${ }^{2,15,22,61}$. Small numbers of $O C$ neurons were recorded from the area of the lamb NTS which receives dense projections from the glossopharyngeal nerve $(6.0 \mathrm{~mm}$ rostral to obex). These more rostral $O C$ neurons had receptive fields located on the tongue, but responses to chemical stimuli were not observed more frequently in these rostral OC neurons compared to $\mathrm{OC}$ neurons located further caudal in the nucleus. However, the small numbers of neurons sampled at these most rostral locations may not be representative of this area as a whole.

\section{Receptive fieids}

Only one neuron in our sample responded to stimulation of both the epiglottis and caudal oral cavity. This suggests that there is little convergence onto NTS neurons of sensory information from receptor populations located in the oral cavity and on the epiglottis. Our results agree with those reported by Sessle ${ }^{52}$ who investigated the responses of neurons in the reflexogenic regions of the cat NTS. Using electrical stimulation of the glossopharyngeal and SLN, he reported only about $3.5 \%$ of NTS neurons received converging input which is similar to the $1.5 \%$ observed in the present study. Other investigations have suggested convergence of glossopharyngeal and SLN in the brainstem using electrical stimulation of the afferent nerves ${ }^{3.14}$. In some cases the differences between the present study and these latter ones can be attributed to the location of the neurons. Biscoe and Sampson ${ }^{3}$ recorded primarily from neurons in the reticular formation beneath the NTS. Sessle ${ }^{52}$ has shown that reticular formation neurons are much more likely to receive converging inputs than neurons in regions of the NTS receiving laryrgeal input. Furthermore, another difference between our findings and those of others is that electrical stimulation of the entire peripheral nerves was used by other investigators. Caution must be used when interpreting the results of whole nerve stimulation studies. Because both the SLN and glossopharyngeal nerve contain fibers responsive to mechanical, chemical and thermal stimuli, stimulation of the whole nerve would activate all these fibers simultaneously which may not be the case with more natural stimuli. In addition, electrical stimulation of the glossopharyngeal nerve would stimulate not only the fibers which innervate the caudal tongue, but also those which innervate the pharynx, while stimulation of the SLN would stimulate laryngeal receptors which might not lie on the epiglottis. In the current study, stimulation of the pharynx was not performed and stimulation of this area might have led to an increase in the amount of observed convergence. The fact that one of the most effective sites for the initiation of some upper airway reflexes is the pharyn $x^{37,47,56}$ suggests that the convergence observed by some studies using electrical stiridation could reflect input from this receptor area.

In contrast to the low numbers of neurons with receptive fields on both the epiglottis and oral cavity, almost $50 \%$ of the OC neurons had two receptive fieids. These receptive fields were located on the tongue and palate and were positioned so that the receptive field on the tongue was directly beneath its counterpart on the palate (Fig. 2). Most of the neurons with two receptive fields responded only to mechanical stimuli which is similar to findings in the rat $\mathrm{NTS}^{44}$. Neurons with multiple receptive fields located in different regions of the oral cavity also have been observed in the rostral regions of the rat, hamster and chicken NTS ${ }^{20,44,63,64}$, and in the parabrachial pons ${ }^{43.45}$, and many neurons in the trigeminal system receive inputs from two or more of the trigeminal divisions ${ }^{1}$. Travers et al.$^{64}$ studied the convergence of gustatory input from different receptor areas onto neurons in the rostral gustatory areas of the NTS. Similar to the results in the present study, they found that neurons which received converging taste inputs usually had receptive fields that were opposite each other on the tongue and palate.

In summary, we have found that the majority of neurons in reflexogenic areas of the NTS responded to more than one stimulus modality and many $O C$ neurons received converging inputs from the tongue 
and palate. This suggests an important integrative function for these neurons in processing information relevant to the elicitation or control of ingestive and protective reflexes.

\section{REFERENCES}

1 Amano, N., Hu, J.W. and Sessle, B.J., Responses of neurons in feline trigeminal subnucleus caudalis (medullary dorsal horn) to cutaneous intraoral and muscle afferent stimuli, J. Neurophysiol., 55 (1986) 227-243.

2 Beckstead, R.M. and Norgren, R., An autoradiographic exanination of the central distribution of the trigeminal, facial glossopharyngeal, and vagal nerves in the monkey, $J$. Comp. Neurol., 184 (1979) 455-472.

3 Biscoe, T.J. and Sampson, S.R., Responses of cells in the brain stem of the cat to stimuiation of the sinus, glossopharyngeal, aortic and superior iaryngeal nerves, J. Physiol. (Lond.), 209 (1970) 359-373.

4 Boushey, H.A., Richardson, P.S. and Widdicombe, J.G., Reflex effects of laryngeal irritation on the pattern of breathing and total lung resistance, J. Physiol. (Lond.), 224 (1972) 501-513.

5 Boushey, H.A., Richardson, P.S., Widdicombe, J.G. and Wise, J.C.M., The response of laryngeal afferent fibres to mechanical and chemical stimuli, J. Physiol. (Lond.), 240 (1974) 153-175.

6 Bradley, R.M., Tapping into the brain, Microcomputing, 62 (1982) 72-79.

7 Bradley, R.M., Cheal, M.L. and Kim, Y.H., Quantitative analysis of developing epiglottal taste buds in sheep, $J$. Anat. 130 (1980) 25-32.

8 Bradley, R.M. and Nistretta, C.M., The morpholegical and functional develupment of fetal gustatory receptors. In N. Emmelin and Y. Zotterman (Eds.), Oral Physiology, Pergamon, Oxford, 1972, pp. 239-253.

9 Bradley, R.M. and Mistretta, C.M., The gustatory sense in foetal sheep during the last third of gestation, J. Physiol. (Lond.), 231 (1973) 271-282.

10 Bradley, R.M. and Mistretta, C.M., Developmental changes in neurophysiological taste responses from the medulla in sheep, Brain Research, 191 (1980) 21-34.

11 Bradley, R.M., Mistretta, C.M., Bates, C.A. and Killackey, H.P., Transganglionic transport of HRP from the circumvallate papilla of the rat, Brain Research, 361 (1985) 154-161.

12 Bradley, R.M., Stedman, H.M. and Mistretta, C.M., S. perior laryngeal nerve response patterns to chemical stimulation of sheep epiglottis, Brain Research, 276 (1983) 81-93.

13 Car, A. and Jean, A., Potentiels évoqués dars le rhombencéphale du mouton par la stimulation du nerf laryngé supérieur. Contribution à l'étude de la lozalisation du centre déglutiteur, J. Physiol. ¿Paris), 63 (1971) 715-730.

14 Ciampini, G. and Jean, A., Rôle Jैles afférences glossopharyngiennes et trigéminales dans le déclenchement et de déroulement de la déglutition. I. Afférences glossopharyngiennes, J. Physiol. (Paris), 76 (1980) 49-60.

15 Contreras, R.J., Beckstead, R.M. and Norgren, R., The central projections of the trigeminal facial glossopharyn-

\section{ACKNOWLEDGEMENTS}

This work was supported by NIH Grant DE05728 to R.M.B.

geal and vagus nerves: an autoradiographic study in the rat, J. Auton. Nerv. Syst., 6 (1982) 303-322.

16 Cottle, M.K., Degeneration studies of primary afferents of IXth and $X$ th cranial nerves in the cat, J. Comp. Neurol., 122 (1964) 329-343.

17 Darian-Smith, I., The trigeminal system. In A. Iggo (Ed.), Handbook of Sensory Physiology, Vol. 2, Somatosensory System, Springer, Berlin, 1973, pp. 271-314.

18 Doty, R.W., Neural organization of deglutition. In C.F. Code (Ed.), Handbook of Physiology, Sect. 6, Alimentary Canal, Vol. 4, American Physiological Society, Washington, D.C., 1968, pp. 1861-1902.

19 Dubner, R., Sessle, B.J. and Storey, A., The Neural Basis of Oral and Facial Funciion, Plenum, New York, 1978, pp. $1-483$.

20 Gentle, M.J., Single unit responses from the solitary complex following oral stimulation in the chicken, J. Comp. Physiol., 130 (1979) 259-264.

21 Halpern, B.P. and Nelson, L.M., Bulbar gustatory responses to anterior and to posterior tongue stimulation in the rat, Am. J. Physiol., 209 (1965) 105-110.

22 Hamilton, R.B. and Norgren, R., Central projections of gustatory nerves in the rat, $J$. Comp. Neurol., 222 (1984) $560-577$.

23 Hanamori, T., Ishiko, N. and Smith, D.V., Multimodal responses of taste neurons in the frog nucleus tractus solitarius, Brain Res. Bull., 18 (1987) 87-97.

24 Hashim, M.A. and Bieger, D., Excitatory action of 5-HT on deglutitive substrates in the rat solitary complex, Brain Res. Bull., 18 (1987) 355-364.

25 Henry, J.L. and Sessle, B.J., Effects of glutamate, substance $P$ and endosin-related peptide on solitary tract neurones involved in respiratic a and respiratory reflexes, $\mathrm{Neu}$ roscience, 14 (1985) 863-873.

26 Jean, A., Localisation et activité des neurones déglutiteurs bulbaires, J. Physiol. (Parisi, 64 (1972) 227-268.

27 Jean, A., Control of the central swallowing program by input from the peripheral receptors. A review, J. Auton. Nerv. Syst., (1984) 225-234.

28 Jean, A. and Car, A., Inputs to the swallowing medullary neurons from the peripheral afferent fibers and the swallowing cortical area, Brain Research, 178 (1979) 567-572.

29 Johnson, P., Robinson, J.S. and Salisbury, D., The onset and control of breathing after birth. In K.S. Comline, K.W. Cross, G.S. Dawes and P.W. Nathanielsz (Eds.), Foetal and Neonatal Physiology, Cambridge University Press, Cambridge, 1973, pp. 217-221.

30 Johnson, P., Salisbury, D.M. and Storey, A.T., Apnoea induced by stimulation of sensory receptors in the larynx. In J.F. Bosma and J. Showacre (Eds.), Development of Upper Respiratory Anatomy and Function: Implications for Sudden Infant Death Syndrome, U.S. Government Printing Office, Washington, D.C., 1975, pp. 160-183.

31 Kovar, I., Selstam, U., Catterton, W.Z., Stahlman, M.T. and Sundell, H.W. Laryngeal chemoreflex in newborn 
lambs: respiratory and swallowing response to salts, acids, and suzars, Pediatr. Res., 13 (1979) 1144-1149.

32 Larson, M.A., McHaffie, J.G. and Stein, B.E., Response properties of nociceptive and low-threshold mechanoreceptive neurons in the hamster superior collicuius, J. Neurosci., 7 (1987) 547-564.

33 Lucier, G.E., Storey, A.T. and Sessle, B.J., Effects of upper respiratory tract stimuli on neonatal respiration: reflex and single neuron analyses in the kitten, Biol. Neonate, 35 (1979) 82-89.

34 Makous, W., Nord, S., Oakley, B. and Pfaffmann, C., The gustatory relay in the medulla. In Y. Zotterman (Ed.), Olfaction and Taste, Pergamon, Oxford, 1963, pp. 381-393.

35 Marui, T., Taste responses in the facial lobe of the carp, $C y$ prinus Carpio L, Brain Research, 120 (1977) 287-298.

36 Mathew, O.P., Sant'Ambrogio, F.B. and Sant'Ambrogio, G., Effects of cooling on laryngeal reflexes in the dog, Resp. Physiol., 66 (1986) 61-70.

37 Miller, A.J., Deglutition, Physiol. Rev., 62 (1982) 129-184.

38 Miller, F.R. and Sherrington, C.S., Some observations on the buccopharyngeal stage of reflex deglutition in the cat, Quart. J. Exp. Physiol., 9 (1916) 147-186.

39 Mistretta, C.M. and Bradley, R.M., Developmental changes in taste responses from glossopharyngeal nerve in sheep and comparisons with chorda tympani responses, Dev. Brain Res., 11 (1983) 107-117.

40 Mistretta, C.M., Gurkan, S. and Bradley, R.M., Morphology of chorda tympani fiber receptive fields and proposed neural rearrangements during development, J. Neurosci., 8 (1988) 73-78.

41 Nomura, S. and Mizuno, N., Central distribution of afferent and efferent components of the glossopharyngeal nerve: an HRP study in the cat, Brain Research, 236 (1982) 1-14.

42 Nomura, S. and Mizuno, N., Central distribution of efferent and afferent components of the cervical branches of the vagus nerve. A HRP study in the cat, Anat. Embryol., 166 (1983) 1-19.

43 Norgren, R. and Pfaffmann, C., The pontine taste area in the rat, Brain Research, 91 (1975) 99-117.

44 Ogawa. H. and Hayama, T., Receptive fields of solitarioparabrachial relay neurons responsive to natural stimulation of the oral cavity in rats, Exp. Brain Res., 54 (1984) 359-366.

45 Ogawa, H., Hayama, T. and Ito, S., Convergence of input from tongue and palate to the parabrachial nucleus neurons of rats, Neurosci. Lett., 28 (1982) 9-14.

46 Ogawa, H., Imoto, T. and Hayama, T., Responsiveness of solitario-parabrachial relay neurons to taste and mechanical stimulation applied to the oral cavity in rats, Exp. Brain Res., 54 (1984) 349-358.

47 Ogura, J.N., Kawasaki, M. and Takenouchi, S., Neurophysiologic observations on the adaptive mechanism of deglutition, Ann. Otol. Rhinol. Laryngol., 73 (1964) 1062-1082.

48 Pfaffmann, C., Erickson, R.P., Frommer, G.P. and Halpern, 1.P., Gustatory discharges in the rat medulla and thalamus. In W.A. Rosenblith (Ed.), Sensory Communica- tion, M.I.T. Press, Cambridge, 1961, pp. 455-473.

49 Pommerenke, W.T., A study of the sensory areas eliciting the swallowing reflex, Am. J. Physiol., 84 (1928) 36-41.

50 Price, D.D., Dubner, R. and Hu, J.W., Trigeminothalamic neurons in nucleus caudalis responsive to tactile, thermal, and nociceptive stimulation of the monkey's face, $J$. Neurophysiol., 39 (1976) 936-953.

51 Rowe, M.J. and Sessle, B.J., Responses of trigeminal ganglion and brainstem neurones in the cat to mechanical and thermal stimulation of the face, Brain Research, 42 (1972) 367-384.

52 Sessle, B.J., Presynaptic excitability changes induced in single laryngeal primary afferent fibres, Brain Research, 53 (1973) 333-342.

53 Sessle, B.J., Excitatory and inhibitory inputs to single neurones in the solitary tract nucleus and adjacent reticular formation, Brain Research, 53 (1973) 319-331.

54 Sessle, B.J., Greenwood, L.F., Lund, J.P. and Lucier, G.E., Effects of upper respiratory tract stimuli on respiration and single respiratory neurons in the adult cat, Exp. Neurol., 61 (1978) 245-259.

55 Shingai, T. and Shimada, K., Reflex swallowing elicited by water and chemical substances applied in the oral cavity, pharynx, and larynx of the rabbit, Jpn. J. Physiol., 26 (1976) 455-469.

56 Sinclair, W.J., Initiation of reflex swallowing from the naso- and oropharynx, Am. J. Physiol., 218 (1970) 956-960.

57 Smith, D.V., Bealer, S.L. and Van Buskirk, R.L., Adaptation and recovery of the rat chorda tympani response to $\mathrm{NaCl}$, Physiol. Behav., 20 (1978) 629-636.

58 Stedman, H.M., Bradley, R.M., Mistretta, C.M. and Bradley, B.E., Chemosensitive responses from the cat epiglottis, Chem. Senses, 5 (1980) 233-245.

59 Storey, A.T., A functional analysis of sensory units innervating epiglottis and larynx, Exp. Neurol., 20 (1968) 366-383.

60 Storey, A.T., Laryngeal initiation of swallowing, Exp. Neurol., 20 (1968) 359-365.

61 Sweazey, R.D. and Bradley, R.M., Central connections of the lingual-tonsillar branch of the glossopharyngeal nerve and the superior laryngeal nerve in lamb, J. Comp. Neurol., 245 (1986) 471-482.

62 Sweazey, R.D. and Bradley, R.M., Response of lamb nucleus of the solitary tract neurons to chemical stimulation of the epiglottis, Brain Research, 439 (1988) 195-210.

63 Sweazey, R.D. and Smith, D.V., Convergence onto hamster medullary taste neurons, Brain Research, 408 (1987) 173-184.

64 Travers, S.P., Pfaffmann, C. and Norgren, R., Convergence of lingual and palatal gustatory neural activity in the nucleus of the solitary tract, Brain Research, 365 (1986) 305-320.

65 Wolf, G., Elementary histology for neuropsychologists. In D.D. Meyers (Ed.), Methods in Psychobiology, Vol. 1, Academic, London, 1971, pp. 283-300.

66 Yamamoto, T., Linguo-hypoglossal reflex: effects of mechanical thermal and taste stimuli, Brain Research, 92 (1975) 499-504. 